\title{
UMA ANÁLISE DE INOVAÇÃO A PARTIR DO ESTUDO DA ADOÇÃO E USO DE TECNOLOGIAS DE AGRICULTURA DE PRECISÃO NA INDÚSTRIA SUCROALCOOLEIRA PAULISTA
}

\author{
Claudia Brito Silva Cirani \\ Doutora em Economia Aplicada pela Universidade de São Paulo - ESALQ/USP \\ Professora Parceira do Programa de Pós-Graduação em Administração da Universidade Nove de Julho \\ - UNINOVE \\ cloubrito@hotmail.com
}

\author{
Marcia Azanha Ferraz Dias Moraes \\ Doutora em Economia pela Universidade de São Paulo - USP \\ Professor doutor da Universidade de São Paulo - USP \\ mafdmora@esalq.usp.br
}

\section{Leonel Cesarino Pêssoa}

Doutor em Direito pela Universidade de São Paulo - USP

Professor do Programa de Pós-Graduação em Administração da Universidade Nove de Julho UNINOVE

lcpessoa@uninove.br

\author{
Dirceu da Silva \\ Doutor em Educação pela Universidade de São Paulo - USP \\ Professor do Programa de Pós-Graduação em Administração da Universidade Nove de Julho - \\ UNINOVE \\ dirceus@uninove.br
}

\section{RESUMO}

As tecnologias de Agricultura de Precisão (AP) já são adotadas nas lavouras do Brasil com técnicas cada vez mais produtivas, importantes para garantir a liderança do país na produção agrícola. No entanto, no Brasil não existem ainda estudos sobre a intensidade do uso de tecnologias de AP. O desafio central deste trabalho foi, então, investigar o processo de adoção e uso dessas técnicas alcançado pela indústria sucroalcooleira no Estado de São Paulo, região que concentra $60 \%$ da produção nacional de cana-de-açúcar. Para tanto, foram utilizados dados primários, a partir do encaminhamento de questionário a todas as empresas do setor sucroalcooleiro da região, com o objetivo de se conhecer, não só o grau de adoção e uso de tecnologias de AP, mas, também, aprofundar a discussão sobre o tema na indústria sucroalcooleira. Assim, foram obtidas informações sobre as características das empresas, as fontes de informação para adoção, os impactos nas empresas e os obstáculos encontrados às práticas das referidas tecnologias. As principais conclusões deste trabalho sugerem que a adoção e uso de práticas de AP trazem resultados positivos para as empresas, como por exemplo, a melhoria no gerenciamento, o aumento da produtividade, a redução dos custos, a minimização dos impactos ambientais e a melhoria da qualidade da cana-de-açúcar.

Palavras-chave: Agricultura de precisão; Cana-de-açúcar; Inovação. 


\section{INTRODUÇÃO}

O Brasil é o maior produtor de cana-de-açúcar do mundo e alcançou 495 milhões de toneladas, processadas na safra 2007/08, de acordo com dados do Ministério da Agricultura, Pecuária e Abastecimento (MAPA). A cana-de-açúcar é cultivada em grande parte do território nacional, mas o Estado de São Paulo lidera a produção. É responsável por $60 \%$ de toda a produção nacional. Graças à sua localização geográfica e sua grande extensão territorial, o Brasil conta com dois períodos de safra distintos. As usinas do Norte-Nordeste colhem a cana-de-açúcar no período que vai de novembro a abril, enquanto as do Centro-Sul têm safra de junho a novembro. Essa característica permite que uma região seja complementada pela produção da outra, em casos de má safra.

Dos 6,96 milhões de hectares ocupados com a cana-de-açúcar na safra 2007/08, 80\% estão na região Centro-Sul e os $20 \%$ restantes, na região Norte-Nordeste. A produtividade média na região Centro-Sul é superior à da região Norte-Nordeste, $83 \mathrm{t}$ ha-1 e 61t ha-1, respectivamente, para safra 2007/08 (CONAB, 2007). Grande parte da superioridade da produção da região Centro-Sul deve-se ao clima, topografia e regime pluviométrico, adequados ao seu plantio.

A maioria das usinas instaladas no Brasil produz açúcar e álcool. Ressalta-se que as usinas de açúcar produzem tanto açúcar quanto álcool ou apenas açúcar, enquanto que as destilarias produzem somente álcool. Segundo dados do MAPA, 59\% das usinas brasileiras são unidades produtoras de açúcar e álcool, ou seja, unidades mistas, 37\% são destilarias de álcool, e os 4\% restantes são produtoras de açúcar.

O Brasil é também líder mundial na produção e exportação dos principais produtos derivados da cana-de-açúcar - o açúcar e o álcool. Em 2008, segundo dados do MAPA, as exportações de açúcar atingiram 19,7 milhões de toneladas, com receitas de US\$ 5,5 bilhões. Quanto ao álcool, 4,8 bilhões de litros foram exportados em 2008. Diante do expressivo aumento da frota nacional de veículos bicombustíveis, que permite a utilização tanto de álcool

quanto de gasolina como combustível e em qualquer grau de mistura, o etanol fabricado da canade-açúcar aparece como uma das alternativas mais competitivas no mundo, quando comparado a outras fontes, já que é uma fonte limpa e renovável de energia, capaz de reduzir as emissões de carbono geradas pela queima de combustíveis fósseis, cujos gases poluentes são provocadores do aquecimento global. Em consequência, a perspectiva é de que as exportações de álcool tenham um crescimento significativo nos próximos anos.

Revista de Administração e Inovação, São Paulo, v. 7, n. 4, p.186-205, out./dez. 2010 
Os custos de produção de açúcar são os menores do mundo. Os custos de produção do etanol de cana-de-açúcar são inferiores ao do etanol derivado de milho nos EUA ou de trigo e de beterraba, na Europa. Essas vantagens comparativas se devem aos avanços de competitividade, que vêm sendo sustentados pela adoção de novas tecnologias, tais como a Agricultura de Precisão (AP) (Macedo, 2007).

O foco da AP é o gerenciamento da variabilidade espacial da produção e dos fatores nela envolvidos, realizado por meio de tecnologias recentes, adaptadas para o meio agrícola, com o objetivo de possibilitar a redução do uso de insumos e do impacto sobre o meio ambiente.

A AP, na atualidade, ganha uma definição mais sistêmica, podendo ser conceituada como uma nova forma de gestão ou de gerenciamento da produção agrícola, e não apenas como um conjunto de ferramentas para o tratamento localizado da lavoura. É um elenco de tecnologias e procedimentos utilizados para que as lavouras e os sistemas de produção sejam otimizados, tendo como elementochave o gerenciamento da variabilidade dos fatores de produção (Swinton \& Deboer, 1998).

O setor sucroalcooleiro vem investindo fortemente na AP. Muitas das tecnologias ainda estão em desenvolvimento, como a aplicação localizada de defensivos e o mapeamento da produtividade (Molin, 2001), e outras já são adotadas plenamente, como por exemplo, a aplicação de fertilizantes e corretivos em taxa variada, a partir de amostragem do solo em grade (Baio, 2006).

Os mapas de produtividade são essenciais na gestão das lavouras sob a ótica da variabilidade espacial. A oferta de monitores para cana-de-açúcar ainda é mínima; apenas recentemente surgiram no mercado maquinários que equipam colhedoras (Magalhães \& Cerri, 2007). No entanto, 60\% da colheita são semimecanizadas, com corte manual.

A tecnologia de piloto automático é favoravelmente adaptada à cultura da cana. Tratores e colhedoras são dirigidos automaticamente, obedecendo às linhas de plantio, visto que a cultura tem um ciclo anual de crescimento, porém o plantio é feito a cada cinco anos. Essa tecnologia permite controle de tráfego e redução da compactação do solo, permite, também, velocidades operacionais maiores com consequente maior rendimento operacional, reduz a fadiga do operador, permite as operações nas 24 horas do dia, permite a redução do consumo de combustível, dentre outras vantagens.

Apesar de estar sendo cada vez mais adotada no Brasil, não existem ainda estudos sobre o processo de adoção e uso de tecnologias de AP no país. O objetivo deste trabalho foi, então, mensurar o grau de adoção e uso dessas tecnologias, verificando quais têm sido mais utilizadas nas usinas/destilarias do Estado de São Paulo e, além disso, obter informações sobre as características das empresas sucroalcooleiras; os impactos das práticas de AP no desempenho das usinas/destilarias; as

Revista de Administração e Inovação, São Paulo, v. 7, n. 4, p.186-205, out./dez. 2010 
fontes de informação utilizadas para a implementação da AP; e os obstáculos encontrados a sua adoção.

\section{REFERENCIAL TEÓRICO}

Das ideias de Joseph Schumpeter, surge a Economia da Inovação, segundo a qual a inovação está no cerne da mudança econômica. Para o autor, as inovações radicais provocam grandes mudanças no mundo, enquanto as inovações incrementais preenchem continuamente o processo de mudança (Schumpeter, 1982). Em Teoria do desenvolvimento econômico, publicado em 1912, ele escreve sobre a existência de vários tipos de inovações, tais como, introdução de um novo produto ou mudança qualitativa de um produto já existente; introdução de processo novo para a empresa; abertura de um novo mercado; desenvolvimento de novas fontes de matérias-primas; e, mudanças na organização da indústria.

A análise do processo de difusão e adoção de novas tecnologias ganha, a cada dia, destaque na literatura econômica. Diferentes escolas do pensamento vêm desenvolvendo teorias que explicam os motivos pelos quais as empresas inovam.

Nos anos 1980, a teoria de Hayami e Ruttan propôs que a inovação tecnológica fosse induzida pela dotação de fatores, dada historicamente, de tal maneira que o fator relativamente escasso fosse poupado e o fator relativamente abundante, usado intensivamente. Como exemplo, os autores citam os Estados Unidos, onde as inovações foram do tipo mecânico, em que o uso da mão de obra era poupado, pois se trata, nesse país, de fator escasso, se comparado à terra. No Japão, contudo, as inovações foram químicas, por ter como fator escasso a terra, ao contrário da mão de obra, que era abundante (Hayami \& Ruttan, 1988).

No modelo de Hayami e Ruttan, a experiência histórica demonstra que, quando a mão de obra torna-se escassa, os produtores e demais forças econômicas e políticas pressionam as instituições de pesquisa para priorizar o desenvolvimento de tecnologias de natureza mecânica, economizadoras de mão de obra. Por outro lado, quando a terra se torna escassa, o esforço dos centros de pesquisa se concentra na criação de tecnologias predominantemente de natureza biológica.

Segundo a teoria da inovação induzida, nesse processo de identificação das oportunidades tecnológicas, desempenha papel fundamental, a existência de um sistema eficiente de informações 
entre os atores (produtores, universidades, instituições públicas de pesquisa, serviços tecnológicos, indústria e empresários).

Além da suposta escassez de mão de obra ou abundância de terra, outras teorias são formuladas para explicar o motivo que leva empresas a buscarem a inovação. A razão apresentada por Schumpeter (1982) é que, se elas estão em busca de lucros, um novo dispositivo tecnológico leva sempre a alguma vantagem para o inovador. Para ele, as empresas inovam para defender suas posições competitivas ou em busca de vantagem competitiva.

Além disso, cada vez mais se entende que a difusão tecnológica apresenta outras características, como, por exemplo, a influência sobre as dinâmicas de mercado que as afastam do equilíbrio. Tal constatação resultou no desenvolvimento mais recente da Economia Evolucionária. Os principais expoentes dessa abordagem, Nelson e Winter (1982), acompanhados por outros participantes da corrente evolucionária neo-schumpeteriana, além de seguirem as principais ideias de Schumpeter da dinâmica da inovação, propõem romper com os pressupostos metodológicos tradicionais de equilíbrio, substituído pela noção mais geral de trajetória; e o de racionalidade maximizadora, substituído pelo de racionalidade limitada ou processual.

A abordagem evolucionária, proposta por Nelson e Winter (1982), baseia-se na interação temporal entre as estratégias empresariais, que envolvem o referido processo de busca de inovações e o processo de seleção, pelo mercado, dessas mesmas inovações. Assim, o principal objeto de análise é a evolução temporal da indústria, em que se vai modificando endogenamente, por meio das inovações e de sua seleção pelo mercado. Portanto, a perspectiva teórica evolucionária procura caracterizar o processo inovador, a partir dos processos de busca e de seleção de inovações.

Os canais e redes, por meio dos quais informações, conhecimentos, ideias e capacidades circulam, são fortemente guiados e restringidos pela estrutura institucional em que a empresa está situada, como por exemplo, universidades, institutos públicos de pesquisa, agências públicas e privadas de fomento ao investimento em inovação e sistema educacional. Lundvall (1992) denominou "Sistemas Nacionais de Inovação" esse conjunto de instituições que contribuem para a inovação e fluxos de conhecimento.

A partir do início da década de 1990, ampliou-se o entendimento do processo de inovação com a elaboração do Manual de Oslo, pela OCDE e a Comissão Europeia, cujo objetivo é servir como orientação para coleta de dados sobre inovação tecnológica (OCDE, 1997). O Manual serve, até hoje, como referência para todas as tentativas de mensuração dos processos de inovação.

Revista de Administração e Inovação, São Paulo, v. 7, n. 4, p.186-205, out./dez. 2010 


\section{METODOLOGIA}

Os dados utilizados neste trabalho foram primários, isto é, obtidos mediante questionários aplicados à indústria sucroalcooleira do Estado de São Paulo. Embora se reconheça a existência de produtores de cana-de-açúcar independentes, responsáveis por aproximadamente $25 \%$ da cana-deaçúcar produzida no Brasil, a pesquisa teve como foco as empresas produtoras de açúcar e álcool verticalmente integradas em direção à material prima.

O período de análise deste estudo foi o ano de 2008 e incluiu todas as usinas/destilarias localizadas no Estado de São Paulo. O levantamento das unidades produtoras de açúcar e álcool foi feito por meio do site da União dos Produtores de Bioenergia (UDOP), cujo portal na internet apresenta uma relação de nomes, endereços, números de telefone e e-mail de todas as usinas/destilarias situadas nesse Estado.

Para assegurar a qualidade das informações, na fase de coleta dos dados, foram adotados alguns procedimentos fundamentais. Primeiramente, identificou-se o diretor ou gerente agrícola de cada usina/destilaria, suficientemente familiarizado com os conceitos de AP e que supostamente teria condição técnica de repassar as informações requeridas. Importante destacar que a identificação dos diretores ou gerentes da área agrícola foi fundamental, neste trabalho, já que as perguntas foram altamente especializadas e só poderiam ser respondidas por pessoas que tivessem autoridade para tomar decisão na empresa e, também, para passar os dados necessários para a realização deste trabalho. Uma vez identificado esse profissional em cada usina/destilaria, por telefone, solicitou-se o preenchimento do questionário, encaminhando-o por e-mail. Os questionários preenchidos foram enviados, também, via e-mail, pelos respondentes.

Para entender alguns aspectos relevantes da relação entre adoção de AP e características da empresa, foram incluídas algumas variáveis no questionário, com o objetivo de identificar: a origem do capital controlador da empresa; se ela é parte de um grupo empresarial ou independente; se a empresa tem gestão profissional ou familiar; o total de cana-de-açúcar moída (em tonelada) na safra 2007/08; a área total (própria e arrendada) explorada com a cana-de-açúcar, em hectares; o número de pessoas ocupadas nas atividades agrícolas da empresa; a estrutura de financiamento dos gastos realizados pela empresa; se ela é exportadora ou não; e as principais parcerias da empresa.

Quanto ao uso da AP, as empresas responderam a quatro perguntas: se adotam ou não AP e quais tecnologias a ela relacionadas têm sido utilizadas; há quantos anos vêm sendo utilizadas na empresa;

Revista de Administração e Inovação, São Paulo, v. 7, n. 4, p.186-205, out./dez. 2010 
se, nos próximos cinco anos, ela pretende expandir, manter ou diminuir tal uso; e se a empresa contrata, integral ou parcialmente, serviços de AP prestados por terceiros.

As atividades de AP, consideradas no questionário, foram de três tipos: aquisição de software; aquisição de máquinas e equipamentos; e treinamentos. Elas apenas foram consideradas atividades de AP quando voltadas especificamente para a implementação de AP. No questionário, foi solicitado que a usina identificasse a importância (alta, média, baixa e não relevante) das três categorias de atividades realizadas nos últimos cinco anos. Dessa forma, foi possível derivar a importância das atividades de AP por meio de uma escala subjetiva.

Em relação aos impactos da AP, o questionário teve por objetivo identificar as mudanças significativas no gerenciamento; melhoria na qualidade da cana-de-açúcar; aumento da produtividade; redução dos custos de produção; redução dos impactos sobre o meio ambiente; ampliação da participação da empresa no mercado; e enquadramento em regulamentações relativas ao mercado interno e externo.

As usinas/destilarias podem obter orientação para adoção de AP de diversas fontes de informação e a sua propensão para adotá-la, certamente, é influenciada pela capacidade de absorver e combinar tais fontes. Assim, a identificação das fontes de informação utilizadas no processo de sua adoção pode ser um indicador do processo de disseminação e absorção da nova tecnologia. $O$ questionário identificou a importância das fontes de informação geradas internamente à empresa, como por exemplo, o departamento de P\&D e outras áreas, e as obtidas através de fontes externas (comerciais, educacionais e de instituições de pesquisa), tal como outra empresa do grupo; fornecedores de máquinas, equipamentos, componentes ou softwares; concorrentes; empresas de consultoria e consultores independentes; universidades e institutos de pesquisa; conferências, encontros e publicações especializadas; e feiras e exposições.

Com respeito aos problemas e obstáculos à adoção, o questionário buscou identificar os motivos por que a usina/destilaria não adotou AP. E, quanto às empresas que as adotam, tornou possível a informação sobre dificuldades ou obstáculos na sua implementação. Assim, tanto para as usinas/destilarias que adotam como para as que não adotam, foi apresentada uma lista de problemas e obstáculos relacionados às tecnologias associadas, solicitando-lhes informar sobre a importância de cada um deles.

Revista de Administração e Inovação, São Paulo, v. 7, n. 4, p.186-205, out./dez. 2010 


\section{ANÁLISE E DISCUSSÃO DOS RESULTADOS}

O índice de respostas obtidas foi satisfatório, uma vez que num universo de 205 usinas/destilarias presentes na região, 87 responderam ao questionário da pesquisa referente ao período de 2008 , de forma completa, o que corresponde a $42 \%$ das empresas sucroalcooleiras do Estado de São Paulo. Ressalta-se que São Paulo é o maior produtor do país e concentra grande parte das usinas/destilarias brasileiras. Nesse Estado, as 205 usinas/destilarias processaram 296 milhões de toneladas na safra 2007/08. Vale chamar a atenção para o fato de que as 87 usinas/destilarias que responderam ao questionário da pesquisa processaram cerca de 170 milhões de toneladas nessa mesma safra, ou seja, $57 \%$ de toda a produção regional.

A Tabela 1 apresenta o grau de adoção e as variáveis relativas ao tamanho (produção, área e pessoal ocupado) das usinas/destilarias que adotam práticas de AP e das que não adotam. Conforme pôde ser observado, mais de $50 \%$ das empresas adotam alguma dessas práticas. De maneira geral, a análise dos dados sugere que essas empresas tendem a apresentar indicadores de escala superiores em relação àquelas que não a adotam. Conforme mostrado na Tabela 1, a produção média de cana-deaçúcar das empresas que adotam foi cerca de 2 vezes superior a das empresas que não adotam. Da mesma forma, a área média foi 1,6 vezes maior e o pessoal ocupado na área agrícola médio, 1,5 superior.

\begin{tabular}{l|c|c|c}
\hline Características & Adotam AP (1) & Não adotam (2) & Índice (1) / (2) \\
\hline Número de empresas & 49 & 38 & 1.29 \\
& $(56 \%)$ & $(44 \%)$ & \\
\hline Produção $^{\mathrm{a}}(\mathrm{t})$ & 2136475 & 1196842 & 1.79 \\
\hline Área $^{\mathrm{b}}$ (ha) & 22103 & 13739 & 1.61 \\
\hline Pessoal ocupado $^{\mathrm{c}}$ & 1570 & 1034 & 1.52 \\
\hline
\end{tabular}

Tabela 1 - Características médias das empresas sucroalcooleiras que adotam e não adotam AP - Estado de São Paulo - 2008.

Fonte: Dados da pesquisa.

\footnotetext{
a Total de cana-de-açúcar moída na safra 2007/08

${ }^{\mathrm{b}}$ Área total (própria e arrendada) explorada com a cana-de-açúcar

${ }^{\mathrm{c}}$ Número de pessoas ocupadas nas atividades agrícolas da empresa
} 
Os dados da Tabela 2 apresentam informações sobre a origem do capital e a orientação exportadora das usinas/destilarias. Constata-se que, para ambas as categorias de empresas, que adotam e não adotam AP, predominam as empresas de capital nacional. Esse resultado é consistente, pois o setor sucroalcooleiro ainda é majoritariamente dominado por empresas brasileiras. Contudo, a tendência é que as empresas estrangeiras cresçam gradualmente nos próximos anos, devido ao atraente custo de produção do açúcar brasileiro e, sobretudo, do álcool, visto como alternativa viável para a substituição de combustíveis fósseis líquidos, em curto e médio prazo. Como se pode observar na Tabela 2, das 79 empresas de propriedade nacional, 58\% adotam alguma prática de AP, enquanto das 8 empresas de capital estrangeiro, $38 \%$ adotam.

Quando se perguntou se a empresa exportava, verificou-se que dentre 67 empresas exportadoras, $66 \%$ adotam AP (Tabela 2). É razoável que o percentual das empresas que adotam AP seja maior entre as exportadoras, já que a exposição à competição do mercado internacional incentiva a empresa a investir em novas tecnologias, para que possa atender à demanda mais exigente e as pressões competitivas mais intensas enfrentadas no mercado internacional.

\begin{tabular}{l|c|c|c|c}
\hline \multirow{2}{*}{ Empresas } & \multicolumn{2}{|c|}{ Origem do capital controlador ${ }^{\mathrm{a}}$} & \multicolumn{2}{c}{ Orientação exportadora $^{-}$} \\
\cline { 2 - 5 } & Nacional & Estrangeiro $^{\mathrm{b}}$ & Exportadora & Não exportadora \\
\hline Que adotam AP & 46 & 3 & 44 & 5 \\
& $(58 \%)$ & $(38 \%)$ & $(66 \%)$ & $(25 \%)$ \\
\hline Que não adotam AP & 33 & 5 & 23 & 15 \\
& $(42 \%)$ & $(63 \%)$ & $(34 \%)$ & $(75 \%)$ \\
\hline Total & 79 & 8 & 67 & 20 \\
& $(100 \%)$ & $(100 \%)$ & $(100 \%)$ & $(100 \%)$ \\
\hline
\end{tabular}

Tabela 2 - Número de empresas sucroalcooleiras que adotam e não adotam AP, segundo a origem do capital controlador e a orientação exportadora - Estado de São Paulo - 2008.

Fonte: Dados da pesquisa.

${ }^{a} \mathrm{O}$ capital controlador é nacional quando está sob titularidade direta ou indireta de pessoas físicas ou jurídicas residentes e domiciliadas no país. O capital controlador é estrangeiro quando está sob titularidade direta ou indireta de pessoas físicas ou jurídicas domiciliadas fora do país

${ }^{\mathrm{b}}$ Aqui são também incluídas as empresas de capital nacional e estrangeiro (mistas) 
Outras duas características das empresas foram identificadas: se a empresa é parte de um grupo empresarial ou independente; e se a sua gestão é profissional ou familiar. Quanto a esse item, os resultados foram extremamente interessantes. Como se pode observar na Tabela 3, dentre as 50 empresas que afirmaram fazer parte de um grupo empresarial, $80 \%$ adotam as tecnologias, enquanto dentre as 37 que declararam ser independente, 24\% as adotam. Este fato pode indicar a existência de sinergias do grupo, tais como uso comum dos equipamentos de AP e troca de informações. Outro resultado interessante é que das 49 empresas que afirmaram possuir gestão profissional, 76\% adotam, enquanto das 38 que declararam ter gestão familiar, 32\% adotam. Assim, é possível observar pela Tabela 3 que as empresas que adotam são predominantemente de gestão profissional e fazem parte de um grupo empresarial.

\begin{tabular}{l|c|c|c|c}
\hline \multirow{2}{*}{ Empresas } & \multicolumn{2}{|c|}{ Grupo ou unidade } & \multicolumn{2}{c}{ Tipo de gestão } \\
\cline { 2 - 5 } & Grupo & Independente & Profissional & Familiar \\
\hline Que adotam AP & 40 & 9 & 37 & 12 \\
& $(80 \%)$ & $(24 \%)$ & $(76 \%)$ & $(32 \%)$ \\
\hline Que não adotam AP & 10 & 28 & 12 & 26 \\
& $(20 \%)$ & $(76 \%)$ & $(24 \%)$ & $(68 \%)$ \\
\hline Total & 50 & 37 & 49 & 38 \\
& $(100 \%)$ & $(100 \%)$ & $(100 \%)$ & $(100 \%)$ \\
\hline
\end{tabular}

Tabela 3 - Número de empresas sucroalcooleiras que adotam e não adotam AP, segundo grupo ou unidade e tipo de gestão - Estado de São Paulo - 2008.

Fonte: Dados da pesquisa.

As empresas informaram também a estrutura de financiamento dos gastos realizados na usina/destilaria. As fontes de financiamento podem ser próprias e de terceiros (privado e público). Conforme mostra a Tabela 4, os recursos próprios parecem ser relativamente mais importantes que as outras fontes de financiamento, independentemente de a empresa adotar ou não AP. Os resultados também mostraram que o percentual de recursos próprios é superior para as empresas que adotam, o que parece ser razoável, pois quanto mais capitalizada estiver a empresa, maiores serão os seus investimentos em máquinas, equipamentos etc. 


\begin{tabular}{l|c|c|c|c}
\hline \multirow{2}{*}{ Empresas } & \multicolumn{4}{|c}{ Fontes de financiamento (\%) } \\
\cline { 2 - 5 } & Próprias & \multicolumn{3}{|c}{ De terceiros } \\
\cline { 2 - 5 } & & Total & Privado & Público \\
\hline Que adotam AP & 77 & 23 & 9 & 14 \\
\hline Que não adotam AP & 58 & 42 & 20 & 22 \\
\hline
\end{tabular}

Tabela 4 - Fontes de financiamento utilizadas pelas usinas/destilarias - Estado de São Paulo $-2008$.

Fonte: Dados da pesquisa.

Não se pode deixar de considerar o custo de oportunidade do capital, que pode ser definido como a rentabilidade que poderá ter o capital em uso alternativo (caso não fosse investido em maquinários e equipamentos para a implementação de AP). Ou seja, a usina/destilaria poderia aplicar no mercado financeiro, considerando as rentabilidades dos investimentos compatíveis com sua aversão ao risco, ao invés de investir em bens de capital. Dessa forma, é importante que a empresa conheça não só o perfil do projeto, mas também a magnitude da taxa de juros ou as alternativas de aplicação no mercado financeiro.

Pode-se afirmar que maior interação entre usinas/destilarias e associações de classe leva ao aprendizado mútuo e à consequente difusão de novas tecnologias. Então, quando foi perguntado se as usinas/destilarias participavam de alguma associação, verificou-se que 79 empresas (91\%) declararam estar associadas a entidades de classe, o que favorece o fomento e a divulgação da adoção da AP. O percentual de usinas/destilarias associadas foi um pouco maior nas empresas que adotam AP (57\%) em relação às empresas que não adotam (43\%).

Buscou-se conhecer, também, cada um dos parceiros com os quais a empresa mantém associação. Como mostra a Figura 1, as usinas/destilarias que adotam AP apontaram União da Indústria de Cana-de-açúcar (UNICA) (76\%) e Centro de Tecnologia Canavieira (CTC) (71\%) como seus principais parceiros, o que destaca a importância da principal associação do setor sucroalcooleiro e centro tecnológico ligado a esse setor no país. Em seguida, assinalaram RIDESA (16\%) e UDOP $(10 \%) 1$.

\footnotetext{
${ }^{1}$ As siglas RIDESA, GERHAI e GMEC significam, respectivamente, Rede Interuniversitária para o Desenvolvimento do Setor Sucroalcooleiro, Grupo de Estudos em RH na Agroindústria, e Grupo de Motomecanização.
} 


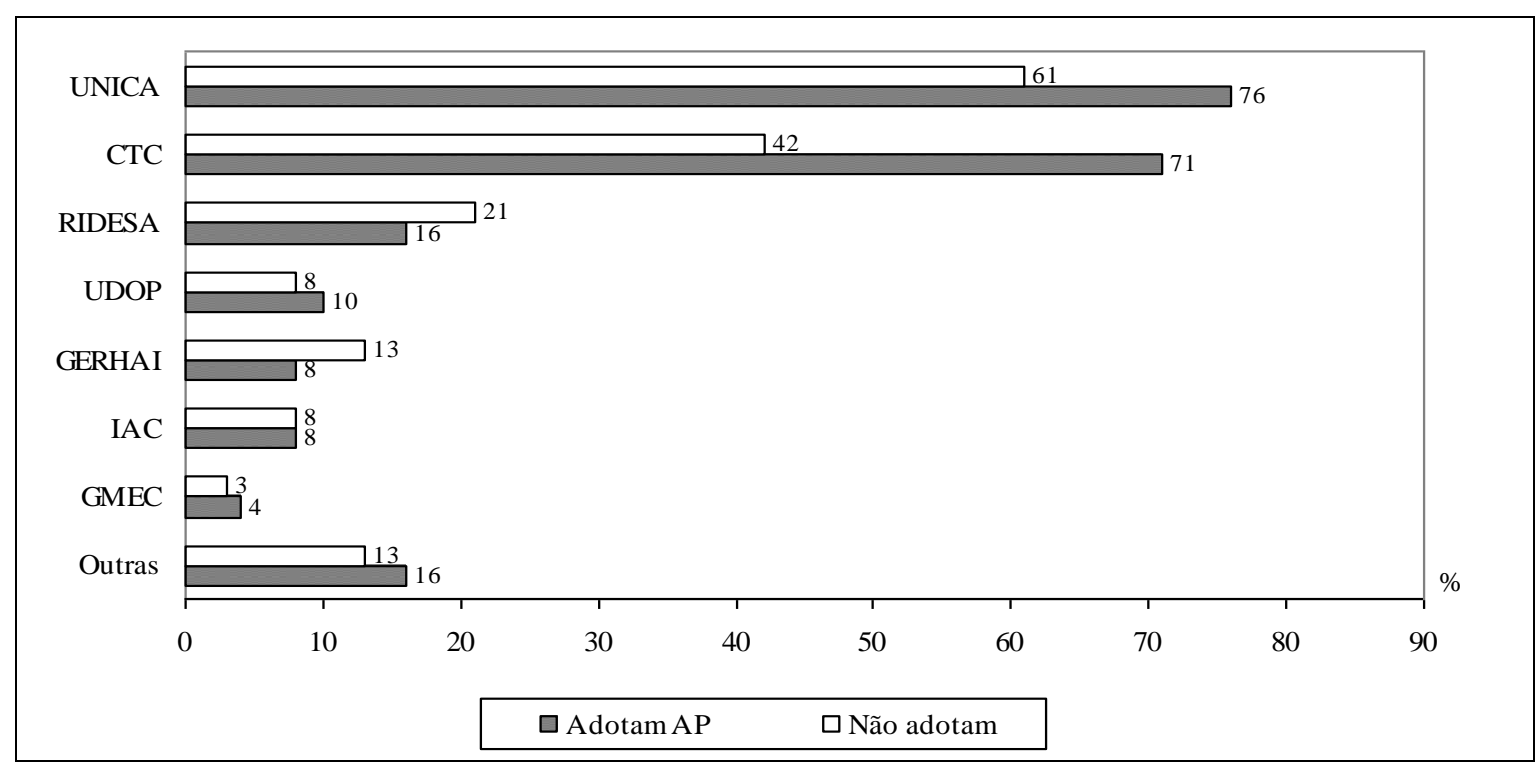

Figura 1 - Associação das usinas/destilarias que adotam e não adotam AP por tipos de parceria - Estado de São Paulo - 2008.

Fonte: Dados da pesquisa.

A Figura 2 resume os resultados da taxa de adoção para as diferentes tecnologias de AP. De mais elevada taxa de adoção é a imagem de satélite, que foi de 76\%. É importante ressaltar que tais imagens, da mesma forma que as fotografias aéreas, com 33\% de adoção, podem não estar diretamente relacionadas às praticas de AP em sua essência, porém foram assim listadas pelos dirigentes.

Das técnicas que merecem maior destaque quanto à taxa de adoção, sobressaem o uso de piloto automático (39\%), a amostragem de solo georreferenciada (31\%) e a aplicação de fertilizantes e corretivos em taxa variável (29\%). O piloto automático é prioritariamente utilizado nos tratores que fazem a abertura de sulcos para o plantio. Algumas usinas/destilarias já o utilizam também nas colhedoras e os tratores equipados acompanham as colhedoras, no transporte interno, o que permite um bom controle de tráfego. Destaca-se que tanto a amostragem de solo georreferenciada como a aplicação de insumos em taxa variável ainda estão exclusivamente associadas ao preparo de solo para replantio, que apenas acontece uma vez a cada cinco anos, em média, em uma mesma lavoura. Tais práticas ainda não são adotadas no cultivo anual, pós-colheita.

Pode-se verificar, também, que as tecnologias com as menores taxas de adoção são: sensores e mapeamento da condutividade elétrica do solo (ambas com 0\%, isto é, nenhuma usina/destilaria adotou-as ainda). Com relação a outras, $4 \%$ das usinas/destilarias apontaram a tecnologia de aplicação de defensivos em taxa variável que, diferentemente da aplicação localizada de fertilizantes e corretivos, está ainda em desenvolvimento.

Revista de Administração e Inovação, São Paulo, v. 7, n. 4, p.186-205, out./dez. 2010 


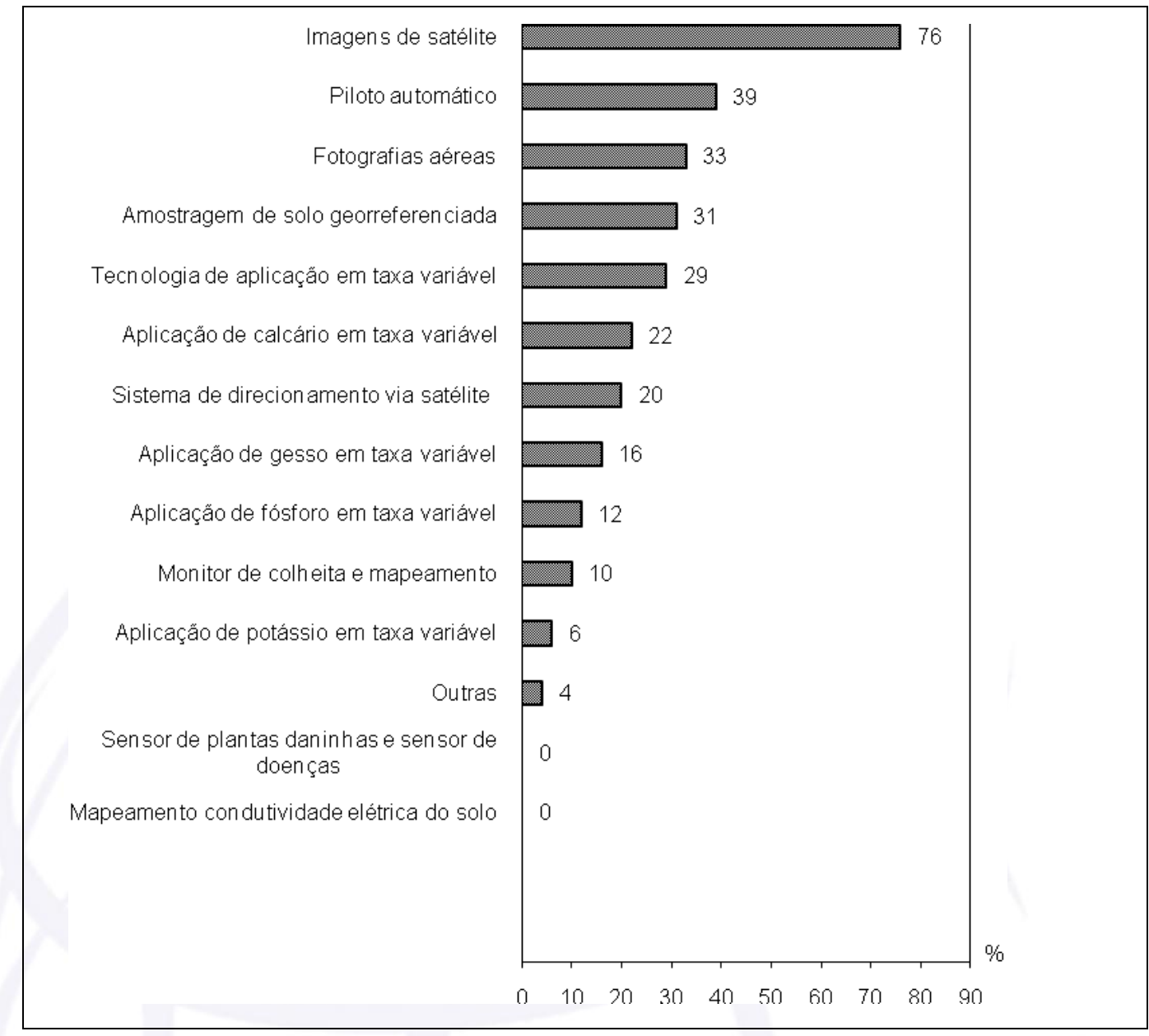

Figura 2 - Taxa de adoção de AP nas empresas sucroalcooleiras, segundo as tecnologias Estado de São Paulo - 2008.

Fonte: Dados da pesquisa.

Quando se observam os dados relativos ao tempo médio de uso de AP nas usinas/destilarias, nota-se que o tempo médio é de quatro anos. Esse resultado consolida, portanto, as evidências de que, apesar de estar sendo adotada, ainda é uma tecnologia relativamente recente no país. No entanto, é possível observar pela Tabela 5 que, mais de $80 \%$ das usinas/destilarias declararam que possuem três ou mais anos de experiência com AP. 
Uma Análise de Inovação a partir do Estudo da Adoção e uso de Tecnologias de Agricultura de Precisão na Indústria Sucroalcooleira Paulista

\begin{tabular}{l|c}
\hline Faixas de tempo & Percentual de empresas \\
\hline 1 a 2 anos & 17 \\
\hline 3 a 4 anos & 31 \\
\hline Mais de 4 anos & 52 \\
\hline
\end{tabular}

Tabela 5 - Percentagem de empresas que adotam AP, segundo faixas de tempo de experiência com as técnicas - Estado de São Paulo - 2008.

Fonte: Dados da pesquisa.

Quando foi perguntado se, nos próximos cinco anos, a empresa pretende expandir, manter ou diminuir o uso de práticas de AP, verificou-se que 96\% das empresas que a adotam declararam seu interesse em aumentar seu uso. Verificou-se também que, apenas 4\% das empresas declararam pretender manter seu uso e nenhuma usina/destilaria declarou ter interesse em diminuir. Esses resultados comprovam o otimismo das usinas/destilarias, o que leva a crer que a AP tornar-se-á ferramenta importante nos próximos anos, não só no âmbito do setor sucroalcooleiro, mas também no das empresas agrícolas brasileiras como um todo.

Em relação ao número de empresas que contratam ou não, integral ou parcialmente, serviços de AP prestados por terceiros, os dados mostram que, cerca de 65\% (32 empresas que a adotam) declararam contratar algum tipo de serviço terceirizado dessa natureza.

Para essas mesmas empresas, destaca-se que as imagens (satélite e fotografias aéreas) foram os serviços terceirizados mais utilizados (69\%). Dentre outros serviços terceirizados contratados pelas usinas/destilarias, destacam-se aplicação de insumos em taxa variável (13\%), piloto automático (9\%) e amostragem de solo georreferenciada (6\%). Vale notar que, estes percentuais são reduzidos e refletem o fato de que os serviços disponíveis ainda não estão perfeitamente adaptados ao setor sucroalcooleiro. Além disso, como se verá adiante, os elevados custos da prestação de serviço é o terceiro obstáculo mais apontado pelas empresas que a adotam.

Com respeito à percepção qualitativa da importância das atividades de AP, os dados deste trabalho revelam que as usinas/destilarias atribuíram importância alta ou média para essas atividades de forma semelhante.

A Tabela 6 mostra a frequência com que as atividades de AP, consideradas neste estudo, foram apontadas pelas usinas/destilarias como de importância alta ou média. No universo de empresas que adotam AP, a maior concentração de respostas atribuiu importância alta ou média para a aquisição de máquinas e equipamentos (75\%), seguida da aquisição de software e treinamento (ambos com $73 \%$ ). 


\begin{tabular}{l|c}
\hline \multicolumn{2}{c}{ Usinas/destilarias que adotam AP } \\
\hline Atividades de AP & Percentual de empresas \\
\hline Aquisição de software & 73 \\
\hline Aquisição de máquinas e equipamentos & 75 \\
\hline Treinamento & 73 \\
\hline
\end{tabular}

Tabela 6 - Percentual de empresas que adotam AP que atribuíram alta ou média importância a atividades de AP - Estado de São Paulo - período 2003-2008.

Fonte: Dados da pesquisa.

Outro aspecto que acrescenta informações relevantes sobre as características do processo de adoção de AP, no setor pesquisado, refere-se às fontes de informação responsáveis pela sua implementação. Elas são consideradas um indicador útil para o entendimento do comportamento das usinas/destilarias, uma vez que a origem de um projeto pode ser proveniente da própria empresa ou de uma fonte externa.

Em relação ao conjunto de empresas que a adotam e que apontaram uma importância alta ou média, aparecem, em primeiro lugar, os fornecedores das referidas tecnologias (92\%), seguidos por universidades e institutos de pesquisa (83\%), conferências, encontros e publicações especializadas (77\%) e empresas de consultoria e consultores independentes (75\%). De uma maneira geral, a análise dos dados sugere que, sua adoção no setor sucroalcooleiro resulta, sobretudo, do uso de informações absorvidas por meio do conhecimento obtido a partir de suas relações comerciais com fornecedores, dos centros educacionais e de pesquisa e das conferências e encontros.

Os resultados que as práticas de AP produzem no desempenho das usinas/destilarias podem ser diversos, podendo ser lucrativos em determinadas situações, mas não em todas. A Tabela 7 apresenta a frequência com que os impactos das referidas práticas, investigados neste trabalho, foram apontados pelas empresas como de importância alta ou média. Para as empresas que a adotam, a mudança significativa no gerenciamento é o impacto apontado com maior frequência (94\%). Em seguida, destaca-se o aumento da produtividade (78\%), a redução do impacto ambiental (73\%) e dos custos de produção (71\%). Esses resultados podem ser corroborados pelo fato de que AP é um sistema de gerenciamento com o objetivo de otimizar os sistemas produtivos e minimizar o impacto ambiental.

Revista de Administração e Inovação, São Paulo, v. 7, n. 4, p.186-205, out./dez. 2010 


\begin{tabular}{l|c}
\hline Usinas/destilarias que adotam AP & Percentual de empresas \\
\hline Impacto causado & 94 \\
\hline Mudanças significativas no gerenciamento & 67 \\
\hline Melhoria da qualidade da cana-de-açúcar & 78 \\
\hline Aumento da produtividade & 71 \\
\hline Redução dos custos de produção & 73 \\
\hline Redução do impacto ambiental & 59 \\
\hline Ampliação da participação da empresa no mercado & 63 \\
\hline Enquadramento em regulamentações relativas ao mercado interno & 57 \\
\hline Enquadramento em regulamentações relativas ao mercado externo & \\
\hline
\end{tabular}

Tabela 7 - Impactos da AP: percentual de empresas que a adotam e que atribuíram alta ou média importância a impactos específicos - Estado de São Paulo - 2008.

Fonte: Dados da pesquisa.

Os motivos pelos quais as usinas/destilarias não adotam AP, ou os obstáculos que encontram na sua implementação constituem informações valiosas para a formulação e avaliação de políticas públicas visando ao aumento do uso de novas tecnologias no setor sucroalcooleiro. Focando, primeiramente, as empresas que adotam essas tecnologias e, analisando a Figura 3, com a proporção de empresas que indicaram importância alta ou média em cada categoria de problemas, percebe-se que seu elevado custo (96\%) é o obstáculo mais apontado pelas usinas/destilarias, seguido por falta de pessoal qualificado (94\%) e elevados custos da prestação de serviço (88\%).

Um número especialmente relevante, a ser observado na Figura 3, é que $82 \%$ das usinas/destilarias que a adotam atribuíram alta ou média importância à falta de informação sobre essas tecnologias. Além dos problemas e obstáculos listados no questionário, algumas usinas/destilarias informaram outros fatores que prejudicam tais práticas como, por exemplo, a inexperiência dos fornecedores que vendem equipamentos, que, na maioria das vezes, não sabem utilizá-los corretamente; ainda não estar perfeitamente desenvolvida para a cana-de-açúcar; e a carência de tecnologias que sejam adequadas às necessidades da usina e que sejam economicamente viáveis.

Com relação aos problemas apontados pelas empresas que não adotam tais tecnologias, os elevados custos da prestação de serviço (97\%) constam como o fator mais relevante, seguido por seus elevados custos (92\%) e falta de pessoal qualificado (89\%), a exemplo do verificado nas 
usinas/destilarias que a adotam. Outros problemas foram apontados pelas usinas/destilarias que não a adotam. Dentre eles, a dificuldade operacional, pois muitas ferramentas estão dimensionadas para grandes áreas; a carência de profissionais especializados, principalmente operadores de máquinas; a legislação e os regulamentos ambientais, exigindo que a usina priorize investimentos em outras áreas; a falta de divulgação e conhecimento de seus benefícios; o prazo muito longo de retorno do investimento; e a resistência à mudança na empresa.

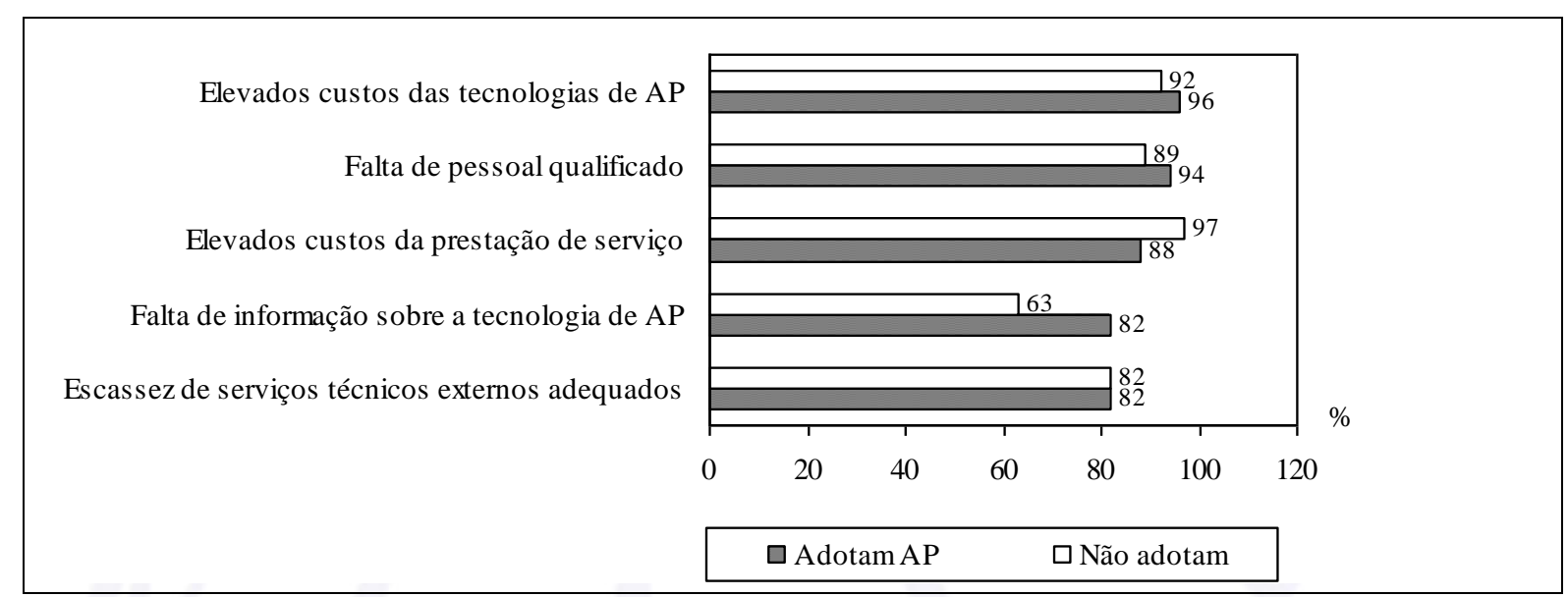

Figura 3 - Problemas e obstáculos apontados pelas usinas/destilarias que adotam e não adotam AP - Estado de São Paulo - 2008.

Fonte: Dados da pesquisa.

Conclui-se que as usinas/destilarias, independentemente de terem adotado a tecnologia, encontraram, nos fatores econômicos, os maiores obstáculos à AP. Dentre eles, o fator considerado como maior obstáculo, foram os elevados custos. Nesse sentido, um dos grandes desafios para a plena adoção dessas tecnologias consiste em reduzir os custos de aquisição dos maquinários e equipamentos. Sabe-se que os preços praticados são decorrentes de falta de escala de produção e nacionalização (Molin, 2004). Além de equipamentos de baixo custo, a adoção em larga escala depende de tecnologias de uso mais simples e mais eficiente, maior percepção de lucratividade pelo uso dessas tecnologias e treinamento de mão de obra especializada (Mattoso \& Garcia, 2006). 


\section{CONSIDERAÇÕES FINAIS}

Há evidências de que o setor sucroalcooleiro vem utilizando a AP em larga escala. Porém, não existem ainda estudos sobre o grau de sua adoção e uso. A falta de pesquisas é consequência da escassez de dados e, também, do fato de se tratar de um campo de estudo ainda recente no país. Dessa forma, este trabalho teve como objetivo investigar o processo de adoção e uso de tecnologias de AP na indústria sucroalcooleira do Estado de São Paulo.

A análise realizada a partir dos dados primários levantados neste trabalho procurou não apenas mensurar o grau de adoção e uso de AP na indústria sucroalcooleira desta região, como também identificar as características das usinas/destilarias, as fontes de informação utilizadas, os impactos e os problemas resultantes de sua adoção.

As principais conclusões deste trabalho sugerem que a adoção e uso de tecnologias de AP trazem resultados positivos para as usinas/destilarias, como por exemplo, a melhoria no gerenciamento da empresa, o aumento da produtividade, a redução dos custos, a minimização dos impactos ambientais e a melhoria da qualidade da cana-de-açúcar.

É indiscutível que a adoção e uso de métodos menos agressivos ao meio ambiente, destinados a melhorar a produtividade e rentabilidade do solo, um fator cada vez mais valorizado, tornar-se-á ferramenta indispensável, nos próximos anos, nas empresas agroindustriais brasileiras. À medida que a AP começa a ser adotada em larga escala, as análises sobre o seu processo de adoção e uso passam constituir informação relevante para a formulação de políticas públicas direcionadas a estimular e apoiar seu uso.

Quanto às ferramentas de políticas públicas para ampliar a difusão de tais tecnologias, a diminuição das taxas de juros e o melhor acesso ao crédito são as principais formas de alcançar esse objetivo. Porém, a dificuldade de acesso ao crédito, conforme visto neste trabalho, é considerada pelas próprias empresas do setor sucroalcooleiro como sendo importante obstáculo à adoção de novas tecnologias. Isso parece indicar a percepção dessas empresas sobre a necessidade da disponibilidade de recursos financeiros a baixo custo para o incentivo do processo de adoção de AP no país.

Espera-se que os resultados obtidos possam subsidiar, notadamente, usinas/destilarias brasileiras, alertando-as para a importância de ferramentas na redução de custos e na minimização dos impactos ambientais, tornando, então, mais competitiva a agroindústria brasileira. Por fim, não se pode deixar de ressaltar que o estudo em questão refere-se à indústria sucroalcooleira do Estado de São Paulo. Entretanto, é fundamental que sejam realizados outros levantamentos, em outras regiões onde a 
tecnologia é adotada. Só assim, será possível obter resultados mais efetivos, mesmo que não objetivem conclusões ou generalizações. Nesse sentido, espera-se que este trabalho possa servir de material instigador para realização de uma diversidade de estudos mais abrangentes que possam levar à compreensão do processo de adoção e uso de AP no Brasil.

\section{REFERENCIAS}

Baio, F. H. R. (2006). Aplicação de A. P. no plantio. In T. C. C. Ripoli, M. L. C. Ripoli, D. V. Casagrandi, \& B. Y. Ide. Plantio de cana-de-açúcar: estado da arte (Cap. 4, p. 92-101). Piracicaba: T. C. C. Ripoli.

Companhia Nacional de Abastecimento - CONAB. (2007). Acompanhamento da safra brasileira de cana-de-açúcar: safra 2007/2008, terceiro levantamento, novembro/2007. Brasília: CONAB. Recuperado em 13 de maio de 2008, de http://www.conab.gov.br/conabweb/download/safra/3_levantamento0708_nov2007.pdf

Hayami, J., \& Ruttan, V. W. (1988). Desenvolvimento agrícola: teoria e experiências internacionais. Tradução de M. V. von Bulow e J. S. W. von Bulow. Brasília, DF: EMBRAPA.

Lundvall, B. A. (1992). National systems of innovation: towards a theory of innovation and interactive learning. London: Pinter Publishers.

Macedo, I. C. (2007). Competitividade da agro-indústria brasileira da cana-de-açúcar. In: Macedo, I. C. A energia da cana-de-açúcar: doze estudos sobre a agroindústria da cana-de-açúcar e a sua sustentabilidade (Cap. 11, p. 191-198). São Paulo: Berlendis \& Vertecchia/UNICA.

Magalhães, P. S. G., \& Cerri, D. G. P. (2007). Yield monitoring of sugar cane. Biosystems Engineering, 96, 1-6.

Mattoso, M. J., \& Garcia, J. C. (2006). Análise econômica da agricultura de precisão. In: Congresso Brasileiro de Agricultura de Precisão. Anais... Piracicaba: USP/ESALQ. 1 CD ROM.

Molin, J. P. (2001). Agricultura de precisão: o gerenciamento da variabilidade. Piracicaba: J.P. MOLIN, 2001. $83 \mathrm{p}$.

Molin, J. P. (2004). Tendências da agricultura de precisão no Brasil. In: Congresso Brasileiro de Agricultura de Precisão. Anais... Piracicaba: USP/ESALQ. p. 1-10.

Nelson, R., \& Winter, S. (1982). An evolutionary theory of economic change. Cambridge: Harvard University Press. 
Organização para Cooperação e Desenvolvimento Econômico. (1997). Manual de Oslo: proposta de diretrizes para coleta e interpretação de dados sobre inovação tecnológica. Rio de Janeiro.

Recuperado em 25 de abril de 2008, de http://www.finep.gov.br/imprensa/sala_imprensa/manual_de_oslo.pdf

Ripoli, T. C. C., Ripoli, M. L. C., Casagrandi, D. V., \& Ide, B. Y. Plantio de cana-de-açúcar: estado da arte (Cap. 4, p. 92-101). Piracicaba: T. C. C. Ripoli.

Schumpeter, J. (1982). Teoria do desenvolvimento econômico. (Coleção Os economistas). São Paulo: Abril Cultural, 1982.

Swinton, S. M., \& Lowenberg-Deboer, J. (1998). Evaluating the profitability of site-specific farming. Madison, Journal of Production Agriculture, 11(4), 439-446.

\title{
ADOPTION AND USE OF PRECISION AGRICULTURE TECHNOLOGIES IN THE SAO PAULO SUGARGANE INDUSTRY: AN INNOVATION ANALYSIS
}

\begin{abstract}
Technologies of Precision Agriculture (PA) have already been implemented in Brazilian plantations, generating an increase of productive techniques, crucial to guarantying the country's supremacy in agricultural production. However, there remain no studies concerning the intensity of PA technology use in Brazil. Thus, the principal challenge of this study was to investigate the process of adopting and using such techniques by the sugarcane industry in the state of Sao Paulo, an area that cultivates $60 \%$ of national sugarcane production. Hence, we used primary data, through a questionnaire submitted to all sugarcane companies within the area, aiming to ascertain not only the degree of adoption and use of such techniques, but to also elaborate on the debate concerned with the sugarcane industry. Therefore, information on the industries' characteristics, sources of information for adopting the technology, and the impact and obstacles encountered for implementing the technology were gathered. The study's prime results suggest that the adoption and use of PA techniques garner positive results for companies, such as: improvement in management; increase in productivity; cost reduction; minimizing environmental impacts and improvement of sugarcane quality.
\end{abstract}

Keywords: Innovation; Precision agriculture; Sugarcane.

Data do recebimento do artigo: 20/08/2010

Data do aceite de publicação: 28/10/2010

Revista de Administração e Inovação, São Paulo, v. 7, n. 4, p.186-205, out./dez. 2010 